\title{
Tribology of rotating band and gun barrel during engraving process under quasi-static and dynamic loading
}

\author{
Bin WU*, Jing ZHENG, Qing-tao TIAN, Zhi-qiang ZOU, Xu-hua YU, Kai-shuan ZHANG \\ Army Officer Academy PLA, No. 451 Huangshan Road, Hefei City, Anhui Province, 230031, China \\ Received: 05 February 2014 / Revised: 05 June 2014 / Accepted: 23 July 2014 \\ (C) The author(s) 2014. This article is published with open access at Springerlink.com
}

\begin{abstract}
The engraving process of a projectile rotating band is one of the most basic research aspects in interior ballistics, which has not been thoroughly understood thus far. An understanding of this process is of great importance from the viewpoints of optimal design, manufacturing, use, and maintenance of gun and projectile. In this paper, the interaction of copper and nylon rotating bands with a CrNiMo gun barrel during engraving was studied under quasi-static and dynamic loading conditions. The quasi-static engraving tests were performed on a CSS-88500 electronic universal testing machine (EUTM) and a special gas-gun-based test rig was designed for dynamic impact engraving of the rotating bands. The mechanical behaviors of copper and nylon were investigated under strain rates of $10^{-3} \mathrm{~s}^{-1}$ and $2 \times 10^{3} \mathrm{~s}^{-1}$ using an MTS 810 and a split Hopkinson pressure bar (SHPB), respectively. Morphologies of the worn surfaces and cross-sectional microstructures were observed with scanning electron microscope (SEM) and optical microscope (OM). It was found that large deformation and severe friction occur during engraving. The surface layer is condensed and correlated with a hardness gradient along the depth from the top worn surface. The structure of the rotating band and gun bore, band material, and loading rate have great effects on band engraving. The flow stress-strain of the copper strongly depends on the applied strain rate. It is suggested that strain rate and temperature play significant roles in the deformation mechanism of rotating bands.
\end{abstract}

Keywords: tribology; sliding friction; plastic deformation; rotating band; gun barrel; engraving; strain rate

\section{Introduction}

Ballistics is the study of the firing, flight, and effect of ammunition, which can be broadly divided into four distinct phases: interior, intermediate, exterior, and terminal. Interior ballistics deals with the motion of a projectile that is still in the gun barrel. A gun barrel is a long, slender tube that serves multiple functions. It often has three major internal regions: combustion chamber, forcing cone, and bore (Fig. 1). The combustion chamber is at the breech-end of the gun barrel and it receives the complete round of ammunition. The forcing cone is the tapered portion near the rear of the bore, connecting the combustion chamber and the bore coaxially. The bore extends from the forcing

* Corresponding author: Bin WU.

E-mail: mewubin@tom.com cone to the muzzle and falls into two general categories: smoothbore and rifled. The former has a completely smooth and cylindrical interior surface, and the latter contains lands and grooves machined axially with a slight twist or helix, causing the projectile to rotate while in the bore. In this paper, rifled gun bore is considered.

The primary function of a large caliber gun is to accurately fire projectiles at high velocities towards a target. Above a certain size, semi-fixed rounds are impracticable because the entire assembly would be too heavy to be carried effectively. Therefore, separate ammunition is loaded in this case, i.e., the projectile and the propelling charges are supplied and loaded separately. The projectile body has three main components that affect ballistics: bourrelet, rotating band, and obturating band (Fig. 2). The external diameter of the projectile is only slightly smaller than that of 


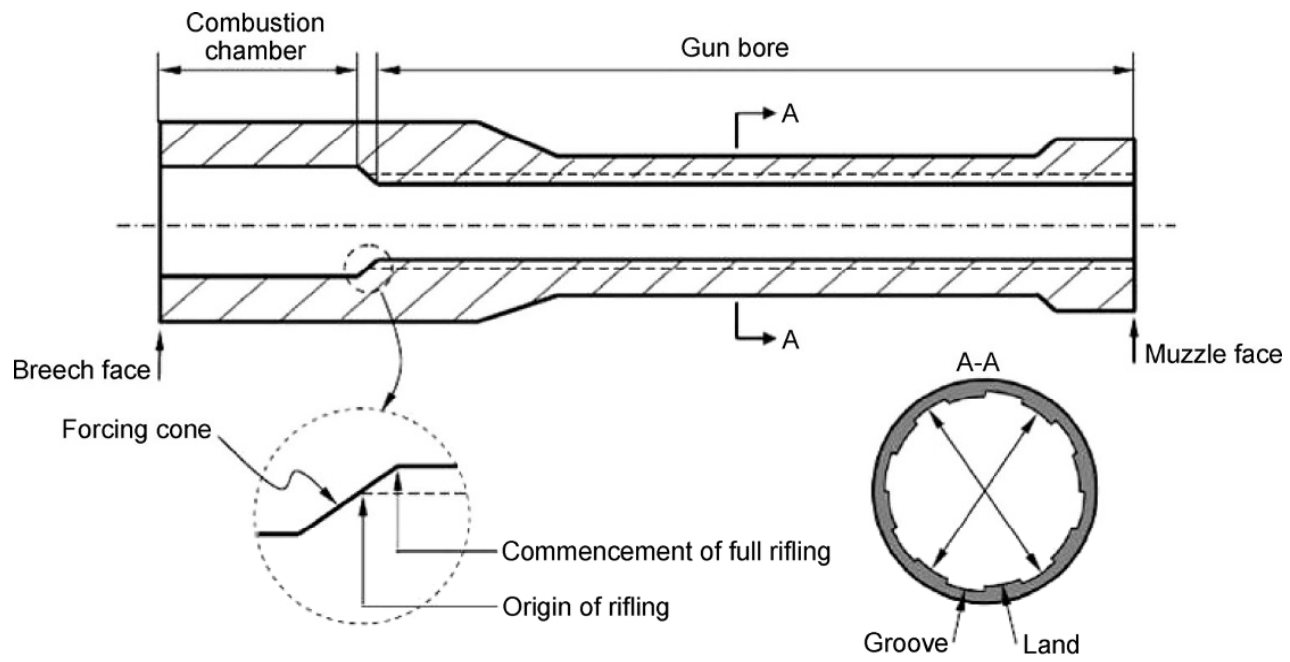

Fig. 1 Schematic diagram of rifled gun barrel.

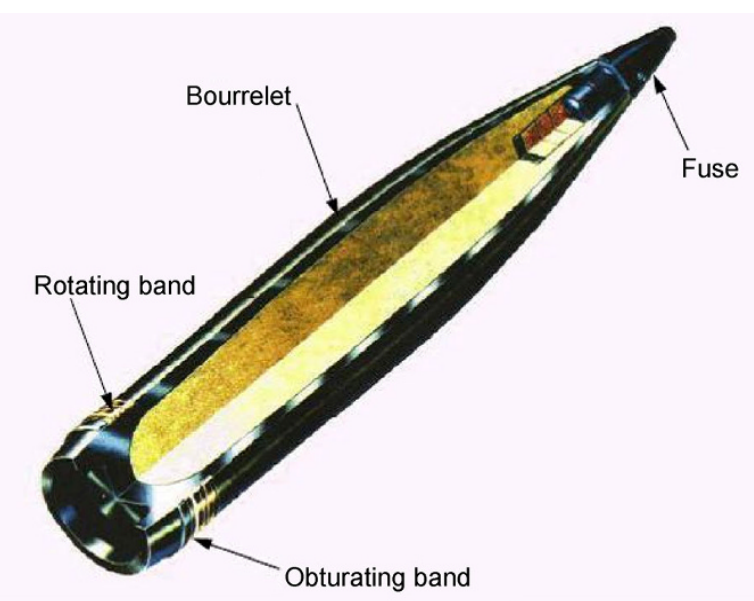

Fig. 2 A projectile with rotating band and obturating band.

the bore, which allows the projectile to slide axially within the bore. The bourrelet centers the forward part of the projectile in the barrel and bears on the lands. The projectiles used in rifled guns of calibers greater than $20 \mathrm{~mm}$ have one or more external bands towards the rear that are slightly larger than the grooves but smaller than the combustion chamber. The functions of a rotating band, also called driving band, are as follows: (1) act as a rear bourrelet and help keep the projectile centered in the bore; (2) prevent the escape of combustion gases past the projectile; (3) provide a repeatable "short-start force" that momentarily resists forward projectile motion while the combustion process is just beginning; (4) engage rifling in the gun bore and transfer the rifling twist to the projectile for creating projectile spin; and (5) retain the projectile in the bore when high angles of elevation are applied. On certain projectiles, the obturating bands are made of plastic to provide forward obturation by preventing the escape of gas pressure from around the projectile.

It is essential that the type of rotating band and its material should be selected properly based on the following considerations: (1) The engraving process should not degrade the ballistic properties after the rotating band has been engraved; (2) the band should be easy to affix and remain attached to the projectile body throughout the internal and external ballistic phases; (3) the band should not wear the bore excessively and compensate for normal wear in the bore. Typically, the rotating band is made of commercially pure copper, copper alloy (gilding metal, bronze, and brass), cupro-nickel alloy, etc.

Upon preparation for firing a large caliber gun, the projectile and propellant are loaded into the gun barrel in two separate processes. The projectile is rammed into the gun barrel, and the rotating band contacts the lands and grooves in the forcing cone. When the gun is fired, the propellant is ignited by the primer, and the burning propellant produces gaseous products of combustion that have very high pressure and temperature. The propellant gases exert a force on the base of the projectile, which begins its forward motion when the gases develop adequate pressure to overcome the "short-start force". The rotating band and the obturating band (if present) will be engraved to the shape of the rifling. 
Continued firing of a gun wears away materials from the forcing cone or bore. This happens either because of the hot gases passing over the cone/bore at high velocities and/or by the projectile moving down bore and interacting with the barrel walls. An excessively worn bore cannot guarantee proper seating of the projectile. Thus, some of the expanding gases could escape from around the rotating band, thus resulting in decreased muzzle velocity. The lands may not engage the rotating band well enough to impart proper spin to the projectile. During loading and the initial stages of combustion, the rotating band is forcibly engraved into the rifling and exerts a radial force on the bore, which can contribute to wear as the projectile traverses the thermally damaged gun bore.

The motion of a projectile in the gun barrel can be divided into two successive stages. The first stage is the engraving of a rotating band into the rifling in a gun barrel, and the second stage is the projectile's acceleration and movement along the gun bore until it exits from the muzzle. The rotating band and the gun bore surface (lands and grooves) compose a friction pair, and the friction between them has different characteristics in each stage. At the beginning of the first stage, the projectile is still initially and is accelerated to a velocity of tens of meters per second within a few microseconds. The projectile's rotating band undergoes plastic deformation at high strain rates when it is engraved by the rifling. Thus, the engraving process is essentially dynamic. The second stage features friction and wear under high sliding speeds, and surface melting is considered as the mechanism of wear. Montgomery [1-5] carried out a series of investigations on the interaction between the rotating band and the gun barrel at high sliding speeds. When a molten film is formed on the surface of rotating band, sliding becomes lubricated and friction is determined hydrodynamically. In this case, the wear of a particular band material is determined by the amount of heat transferred to it. A portion of the melted surface layer is removed, which means that high melting is essential for the rotating band material to have good wear resistance. A slider melting wear theory was proposed by Matsuyama based on the non-steady heat conduction equation [6], and he established a practical, thermal property-based selection process for slider materials such as red brass, Al-bronze, and brass. Lisov investigated the wear mechanisms of 105- and 155-mm artillery projectiles' rotating bands theoretically and experimentally using variable parameters of internal ballistics [7]. Based on the measured strain of the barrel's exterior surface, Andrews [8] found that high charges generally degrade the rotating band by reducing the load the rotating band applies to the $155 \mathrm{~mm}$ gun barrel during firing. The influence of rotating band construction on gun tube loading was investigated experimentally and numerically by Toivola et al. [9] and Keinänen et al. [10]. They presented a practical analysis method for determining the tube inner wall pressure from outer wall strain measurements, and the generated numerical results were in agreement with the measured firing results. Eleiche et al. [11] proposed the use of glass-fiber reinforced polyamide as an alternative material for rotating bands and found that PA66 resin with $2 \%$ GF reinforcement offers the ideal compromise; the rotating band withstands the associated plastic deformation without failure at all sliding speeds. The interaction between the projectile driving band and the forcing cone of a weapon barrel in the course of ramming was studied by Balla et al. [12]. It was found that the ramming and extraction forces depend remarkably on the degree of wear of the forcing cone diameter.

As mentioned above, although there are few published studies on the interaction between the rotating band and the gun barrel, insight into the engraving process is in great demand in the field of interior ballistics. Chen $[13,14]$ performed a large deformation analysis of the engraving process and wear in a projectile rotating band by using the finite element program ABAQUS. An elastic-plastic material model was chosen for the copper band, and an appropriate coefficient of sliding friction was selected. The calculated finite element results showed that band pressure is large, and severe plastic deformation occurs in the band. Because the rotating band is hidden from view during the engraving process, its deformation cannot be measured as it occurs. As is known, the engraving process involves a system composed of the gun barrel, projectile, and propellant as shown in Fig. 3 [15]. Combustion of the propellant 


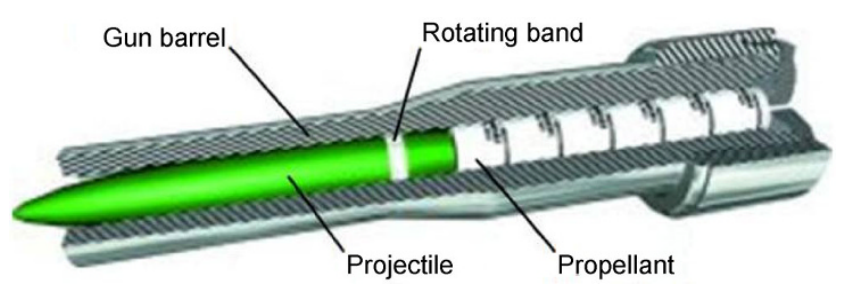

Fig. 3 Gun-projectile-propellant system.

generates high pressure, which acts on the projectile base and pushes it through the forcing cone and then down the rifled bore. Many parameters influence the band/barrel interaction, such as type and amount of propellant; structures, geometries, and materials of band and gun bore; and friction condition (dry or lubricated). Obviously, it is very difficult to analyze the engraving process theoretically given its complexity. The quasi-static pushing test method has been adopted by pressing the rotating band inside a portion of a barrel section with a universal testing machine [16]. However, this method is conducted at very low speeds in comparison with actual firing. Therefore, the key to investigating the engraving process experimentally is the generation of dynamic forces that simulate the action of gas pressure. In this paper, a gas-gun-based test rig was designed and constructed specially for generating the impact force required to engrave the rotating band. Moreover, quasi-static engraving tests were carried out using a CSS-88500 electronic universal testing machine (EUTM) for comparison with the results of dynamic testing. The friction and deformation behavior of the rotating bands were observed after engraving. The possible deformation mechanism of rotating bands was investigated under different loading conditions.

\section{Experimental studies}

\subsection{Simulated gun barrel and projectile}

Figure 4 shows the schematic representation of a simulated gun barrel section and projectile. A hollow CrNiMoV steel cylinder with a length of $225 \mathrm{~mm}$, inner diameter of $72 \mathrm{~mm}$, and outer diameter of $100 \mathrm{~mm}$ was chosen. Twenty-four lands and grooves were cut by electrical discharge machining and then polished mechanically to a mean surface roughness of about $0.4 \mu \mathrm{m}$ with a standard deviation of $0.12 \mu \mathrm{m}$. It should be noted that linear rifling, namely, rifling profile without a twist, was adopted in our tests for two reasons. One is that the main aim of the current study is to investigate the engraving of the rotating band. The engraving process ends when the band has been engraved into the forcing cone completely and reaches the commencement of full rifling. Therefore, whether the rifling is linear has little influence on the engraving

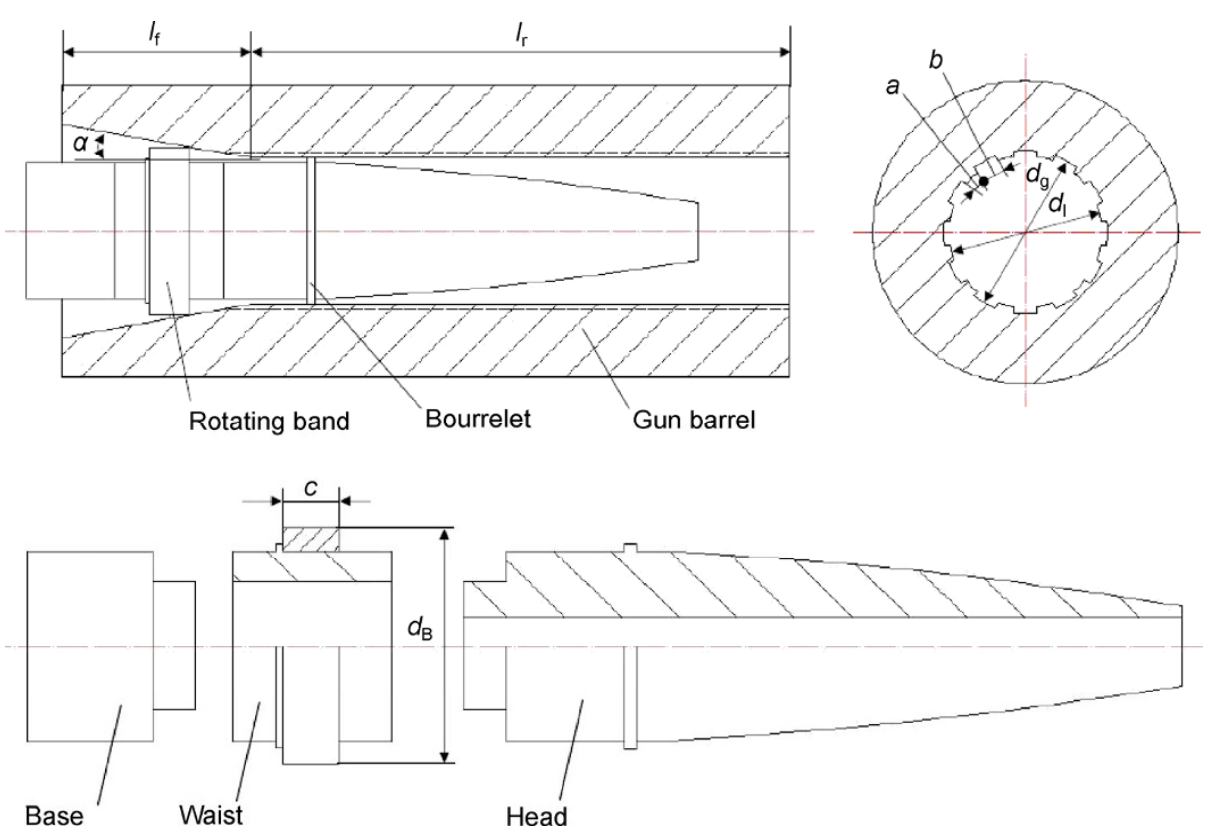

Fig. 4 Schematic of simulated gun barrel and projectile design. 
process. The other reason is that linear lands are easy to cut, and subsequent theoretical analysis of interaction between the band and rifling could be performed. The diameters of the lands and grooves are $74.5 \mathrm{~mm}$ and $76.5 \mathrm{~mm}$, respectively, that is to say, the barrel rifling depth is $1 \mathrm{~mm}$. The width of each land is $3 \mathrm{~mm}$ and that of the groove is about $7 \mathrm{~mm}$. The length and half angle of the forcing cone are $47.7 \mathrm{~mm}$ and $1.5^{\circ}$, respectively.

Before engraving, the rotating band of copper or nylon ring was machined on the lathe and then pressed onto the projectile's waist using an oil press. A mean surface roughness of about $0.8 \mu \mathrm{m}$ with a standard deviation of $0.38 \mathrm{~mm}$ was achieved for the rotating band. After engraving, the rotating band cannot be separated from the waist owing to interference fits between them. To avoid damage to the engraved rotating band, the projectile was designed to have three parts: base, waist, and head. The base and head were screwed to the waist before testing and broken from the waist after testing. Therefore, the base and head can be used repeatedly, and only the waist with the rotating band has to be replaced. The diameter and width of the rotating band were $76.7 \mathrm{~mm}$ and 10-25 mm, respectively. Figure 5(a) shows the simulated gun barrel section, and Fig. 5(b) shows the gun barrel-projectile combination. Waists with copper (T2) and nylon (1010) rotating bands are shown in Figs. 5(c) and (d), respectively. (a)

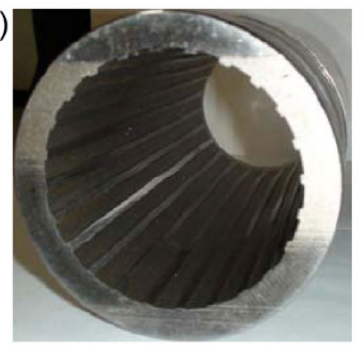

(c)

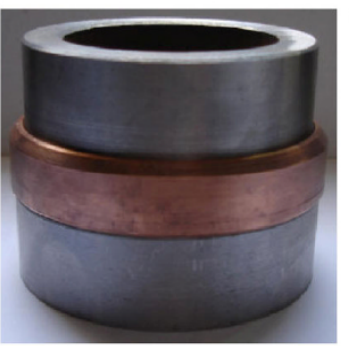

(b)

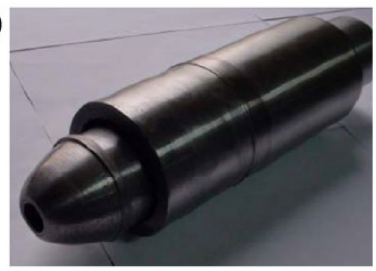

(d)

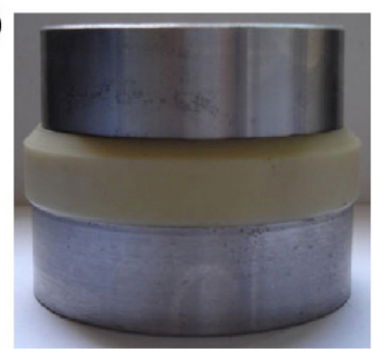

Fig. 5 Gun barrel and rotating bands for engraving test: (a) gun barrel; (b) the gun barrel-projectile combination; (c) copper band; (d) nylon band.

\subsection{Quasi-static and dynamic loading methods}

A CSS-88500 EUTM was employed to perform quasistatic engraving experiments, as shown in Fig. 6(a). Crosshead speeds of 0.5, 1.0, 3.0, 5.0, 10.0, and $30 \mathrm{~mm} \cdot \mathrm{min}^{-1}$ were employed and the required engraving force was recorded electronically as a function of displacement and displayed on the screen. When copper bands were tested, a decoppering agent was used to clean the gun bore surface thoroughly in order to maintain the same boundary condition for the next test. Linear and angular alignment of the crosshead and projectile (rotating band) is critically important in experiments. During the first test process of engraving the copper band (Copper $1^{\#}$, listed in Table 1), abnormalities were observed in the engraving force curve after engraving, as shown in Fig. 6(b). When the projectile was pushed out of the barrel exit, engraved scars were observed on the edge of waist body (Fig. 6(c)). Therefore, a universal joint, shown in Fig. 6(d), was adopted in all subsequent tests to correct the slight misalignment along the loading axis.

As is known, the engraving characteristic of the rotating band under actual firing conditions is dynamic. Severe friction between the band and the rifling occurs, and the rotating band undergoes large plastic deformation. To realize dynamic loading on the projectile and reproduce the band-bore interaction to the greatest extent, we designed and constructed a gas-gun-based dynamic impact test rig, as shown in Fig. 7. Before the test, the gun barrel was mounted tightly on the base, and the projectile combined with the rotating band to be engraved was placed in the gun bore. The gas pressure of the gun was adjusted with a pressure control system. Upon opening the valve, the striker bar is launched by the gas such as compressed air, nitrogen, or helium in the pressure storage vessel. The striker bar accelerates and moves forward along the gas gun tube until it impacts the projectile's base. Under the impact loading, the rotating band is extruded into the forcing cone and shaped by the rifling. The projectile is subsequently discharged out of the barrel and recovered for analysis. On the gas gun tube side near the exit, gas venting holes are drilled to ensure that constant speeds of the striker bar can be obtained. The striking velocities just before impact were measured using a laser velocimeter. The 
(a)

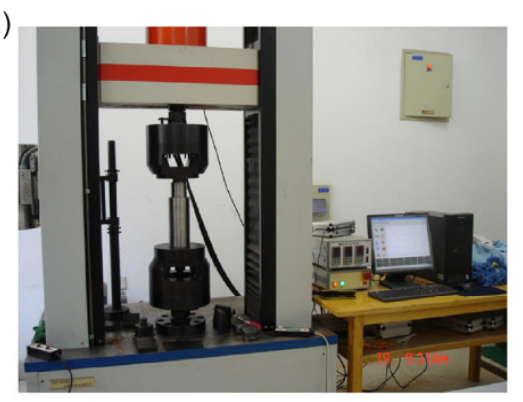

(c)

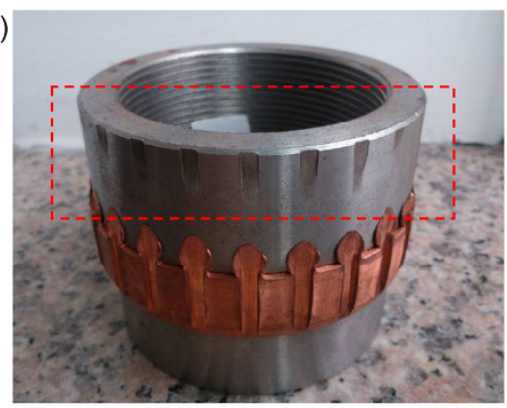

(b)

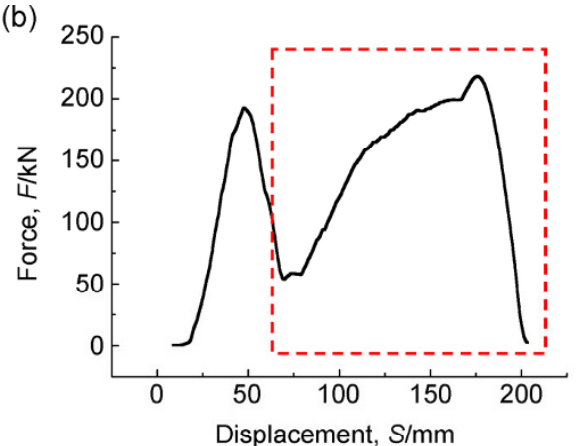

(d)

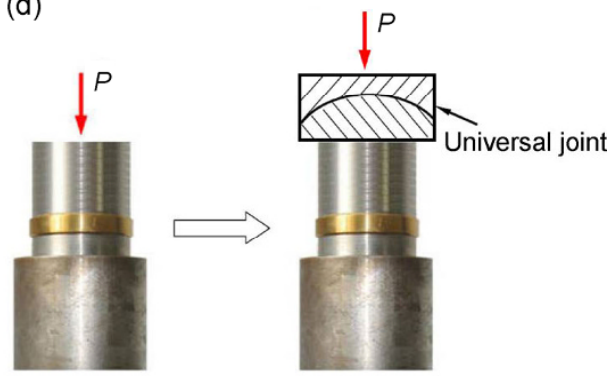

Fig. 6 Quasi-static engraving tests on EUTM.

Table 1 Test conditions and results.

\begin{tabular}{ccccccc}
\hline $\begin{array}{c}\text { Rotating } \\
\text { band }\end{array}$ & $d_{\mathrm{B}}$ & $c$ & $\delta$ & $R_{\mathrm{L}}$ & Lubrication & $F_{\max }$ \\
\hline Copper 1 $^{\#}$ & 77 & 15 & 0.25 & 30 & No & 192.97 \\
Copper 2 $^{\#}$ & 76.7 & 15 & 0.1 & 30 & No & 83.78 \\
Copper 3 $^{\#}$ & 76.7 & 10 & 0.1 & 30 & No & 59.64 \\
Nylon 1 $^{\#}$ & 76.7 & 15 & 0.1 & 30 & No & 6.95 \\
Nylon 2 $^{\#}$ & 76.7 & 15 & 0.1 & 30 & Oiled bore & 5.42 \\
Nylon 3 $^{\#}$ & 76.7 & 15 & 0.1 & 1 & No & 4.56 \\
\hline
\end{tabular}

striking speed can be adjusted simply by changing the gas pressure in the vessel and/or the depth of the striker bar inside the gas gun tube. The loading duration is proportional to the length of the striker bar. It should be noted that the striker bar, projectile (rotating band), and gun barrel are fixed and adjusted accurately to be coaxial with each other prior to the test. Furthermore, gas leakage between the sealing ring and gas gun tube has a negative effect on the stability of the striking speed. In this study, we used a striker bar made of high strength steel and having a diameter of $75 \mathrm{~mm}$ and a length of $800 \mathrm{~mm}$. Nitrogen was used at gas pressures of $0.3,0.4,0.5,0.6$, and $0.7 \mathrm{MPa}$, and the measured striking velocity ranged from $2 \mathrm{~m} / \mathrm{s}$ to $5 \mathrm{~m} / \mathrm{s}$. According to the best of our knowledge, no specific work has been conducted on the engraving process of a projectile rotating band under dynamic loading by using a gas gun.

\subsection{Mechanical behavior of band materials}

The rotating band materials deform at low and high strain rates in the quasi-static and dynamic engraving processes, respectively. Knowledge of the mechanical behavior of materials is beneficial for gaining insight into engraving behavior. Two materials were tested, namely, copper (T2), and nylon (1010). The current quasi-static loading experiments were performed under a strain rate of $10^{-3} \mathrm{~s}^{-1}$ using an MTS 810 material testing system. The dynamic impact tests were conducted under a strain rate of $2 \times 10^{3}$ using a compressive split Hopkinson pressure bar (SHPB), as shown in Fig. 8. Cylindrical specimens measuring $6 \mathrm{~mm} \times 8 \mathrm{~mm}$ (diameter $\times$ length) were prepared and positioned between an incident bar and a transmission bar, both of which were made from high strength spring steel and had diameters of $14.5 \mathrm{~mm}$. Prior to testing, the end faces of each cylindrical specimen were lubricated with silicon grease to minimize friction during impact testing. Stress pulses were detected using electroresistance strain gauges mounted on the incident and the transmission bars. 

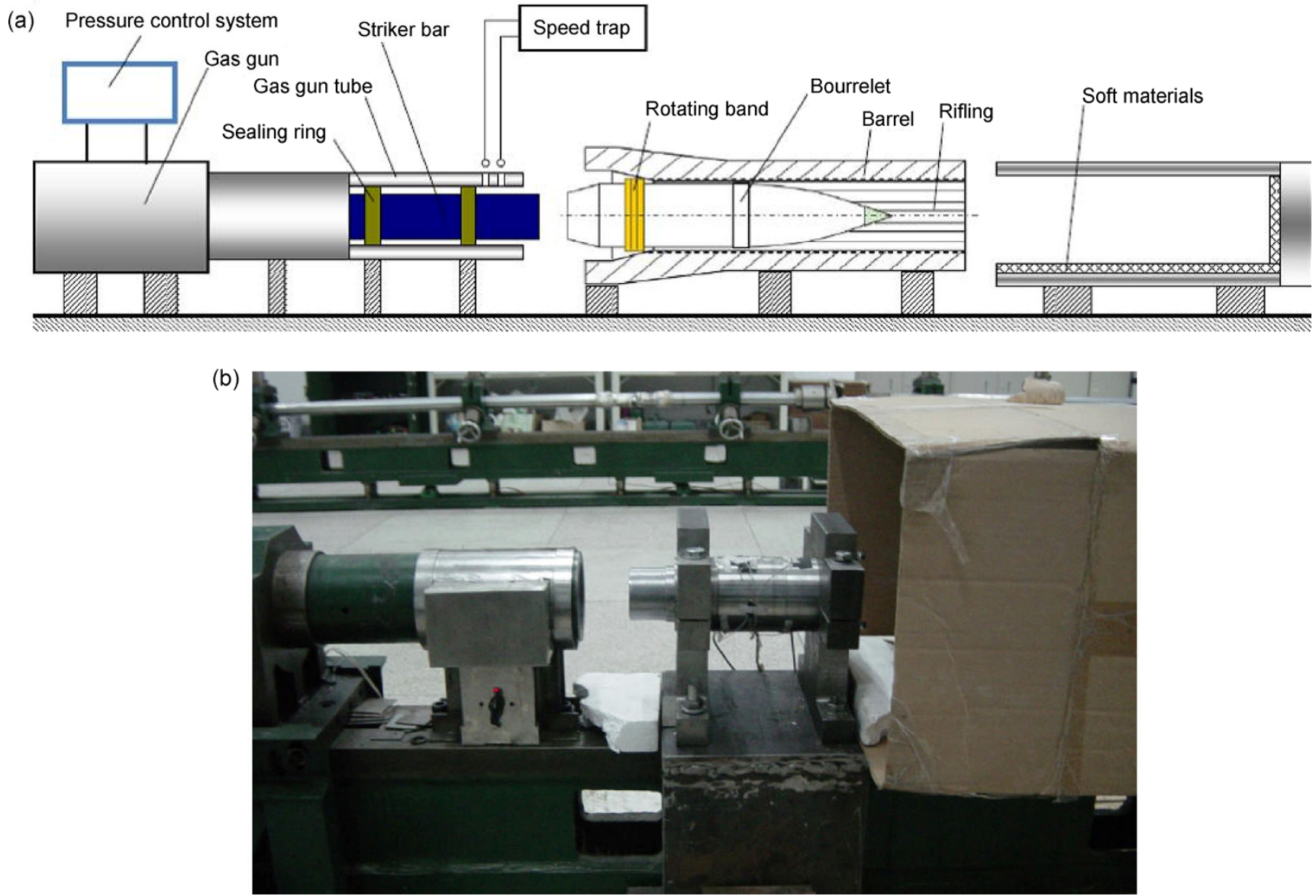

Fig. 7 A gas-gun-based dynamic impact test rig.

(a)

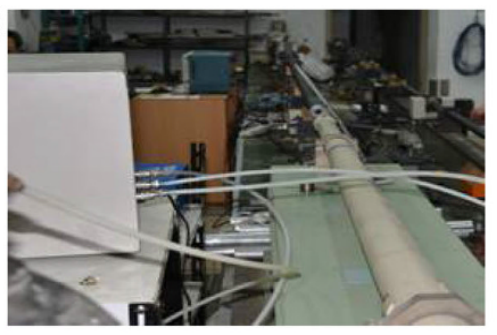

(c)

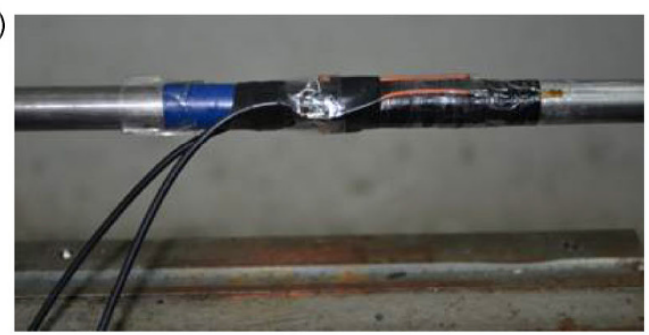

(b)

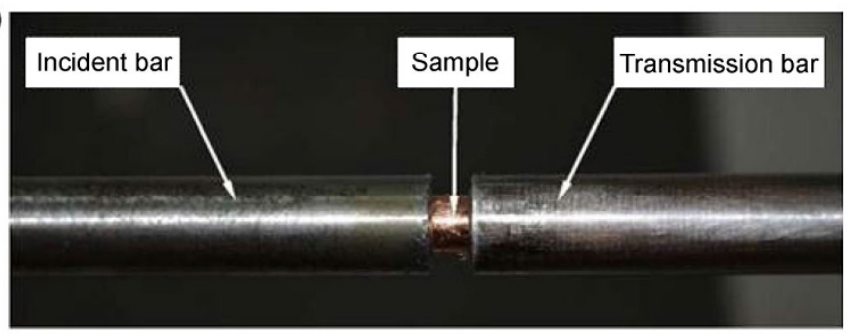

Fig. 8 Photograph of SHPB system. 


\subsection{Morphology observation}

The morphologies of the worn surfaces of rotating bands under quasi-static and dynamic engraving conditions were investigated with a scanning electron microscope (SEM, Philips of Holland, Model XL30 ESEM-TMP) at an operating voltage of $20 \mathrm{kV}$. The samples were cleaned ultrasonically in acetone for about 15 min before SEM observation. Energy dispersive spectroscopy (EDS) was used to analyze the composition of the worn surface.

Because of severe plastic deformation and friction during the engraving process, the microstructure in the surface layer was effectively refined, and a different microstructure was obtained as a result of the different strain rate. Samples of cross-sectional surfaces to be viewed using optical microscope $(\mathrm{OM})$ were polished before etching. Polishing was performed using various grades of sandpaper, followed by polishing with $1 \mu \mathrm{m}$, $0.5 \mu \mathrm{m}$, and $0.25 \mu \mathrm{m}$ diamond suspensions. After polishing, the samples were etched using a $10 \mathrm{ml} \mathrm{HCl}$ solution, $10 \mathrm{~g} \mathrm{FeCl}_{3}$, and $120 \mathrm{~mL} \mathrm{H}_{2} \mathrm{O}$.

\section{Results and discussion}

\subsection{Quasi-static engraving of rotating bands}

Experimental results of engraved copper and nylon rotating bands under quasi-static loading are shown in Fig. 9. Large deformation and severe friction occurred after engraving. The rotating bands were extruded by the lands to form corresponding grooves. The band material accumulated at the end of every groove did not separate from the band. Moreover, there was severe friction between the rotating band surface and grooves of gun bore. We compare the rifled gun bore (lands and grooves) to a shaped tool. Under low speed loading, the rotating band was not cut but extruded by this blunt tool.

Some testing results are listed in Table 1 , where $\delta=\left(d_{\mathrm{B}}-d_{\mathrm{g}}\right) / 2, R_{\mathrm{L}}$ refers to the loading rate, and $F_{\max }$ refers to the maximum engraving force. It was shown that the rotating band materials, rotating band structure, gun bore structure, and loading rate influence the engraving process. Under the same testing conditions, the maximum engraving force of the copper rotating band is an order of magnitude higher than that of the nylon rotating band. For (a)

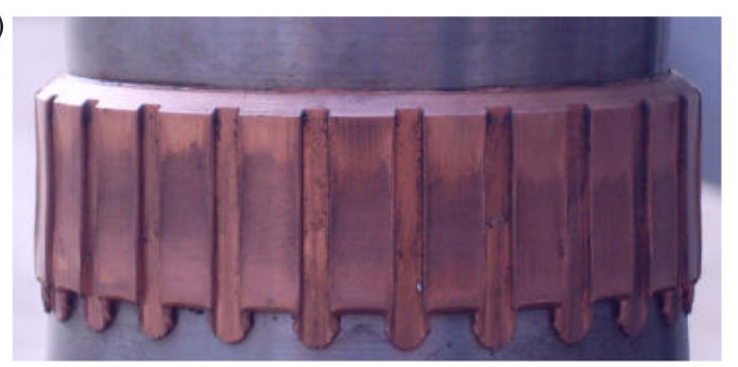

(b)

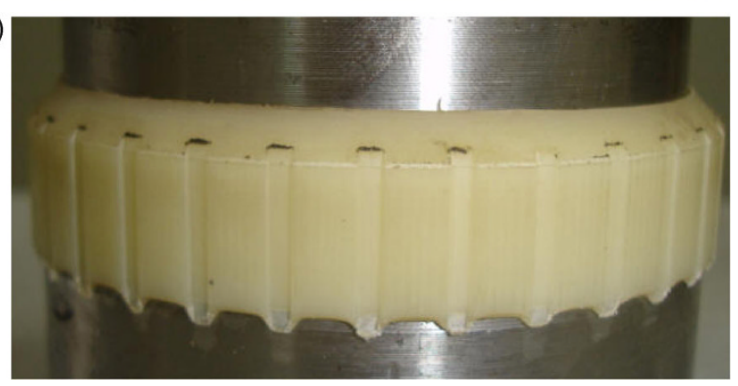

Fig. 9 Quasi-static engraved rotating band: (a) copper; (b) nylon.

example, for $d_{\mathrm{B}}=76.7 \mathrm{~mm}, c=15 \mathrm{~mm}, \delta=0.1 \mathrm{~mm}$, $R_{\mathrm{L}}=30 \mathrm{~mm} \cdot \mathrm{min}^{-1}$, the maximum engraving force for the nylon rotating band was $6.95 \mathrm{kN}$ and that for the copper rotating band was $83.78 \mathrm{kN}$. The maximum engraving force on the copper rotating band increased from $83.78 \mathrm{kN}$ to $192.97 \mathrm{kN}$ when $\delta$ was increased from $0.1 \mathrm{~mm}$ to $0.25 \mathrm{~mm}$. When $c$ was increased from $10 \mathrm{~mm}$ to $15 \mathrm{~mm}$, the maximum engraving force increased from $59.64 \mathrm{kN}$ to $83.78 \mathrm{kN}$. For the nylon rotating band, the maximum engraving force decreased from $6.95 \mathrm{kN}$ to $5.42 \mathrm{kN}$ for a dry gun bore surface under lubricated condition. As the loading rate was decreased from $30 \mathrm{~mm} \cdot \mathrm{min}^{-1}$ to $1 \mathrm{~mm} \cdot \mathrm{min}^{-1}$, the maximum engraving force for the nylon rotating band decreased from $6.95 \mathrm{kN}$ to $4.56 \mathrm{kN}$.

Figure 10 shows the force histories for engraving copper $2^{\sharp}$, copper $3^{\sharp}$, nylon $1^{\sharp}$, nylon $2^{\sharp}$, and nylon $3^{\sharp}$ rotating bands. It can be seen that the engraving force increased nearly linearly with displacement. When rotating band was completely engraved, the force reached the maximum, then decreased gradually, and dropped to zero when the rotating band was pushed out of the barrel (not shown in Fig. 10). The average required force per millimeter before the maximum force was $4.43,3.47,0.43,0.37$, and $0.32 \mathrm{kN} / \mathrm{mm}$, respectively. Higher force was needed to overcome the resistance during the engraving of the copper rotating band than that of the nylon rotating band. Before the rotating band was engraved completely, the resistance 


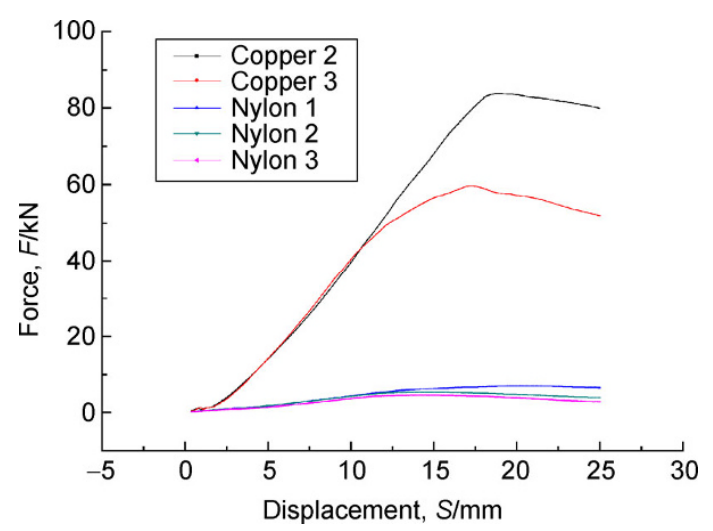

Fig. 10 Force vs. displacement for engraving rotating bands.

was composed of two parts: one due to rotating band deformation and the other induced by friction between the rotating band and the gun bore. After complete engraving, the resistance decreased because rotating band deformed no longer, and only sliding friction added to the resistance. For example, the force history of engraving of a nylon rotating band is shown in Fig. 11. The maximum engraving force approached $7.37 \mathrm{kN}$ when the nylon rotating band was completely engraved, which decreased to $\sim 6 \mathrm{kN}$ when the band was moving forward over straight lands and grooves.

\subsection{Dynamic impact engraving of rotating bands}

The dynamic impact engraving of copper and nylon rotating bands having a diameter of $76.7 \mathrm{~mm}$ diameter and a width of $15 \mathrm{~mm}$ are shown in Fig. 12. As we know, the rotating band is engraved into the forcing cone by the pressure of combustion gas under actual

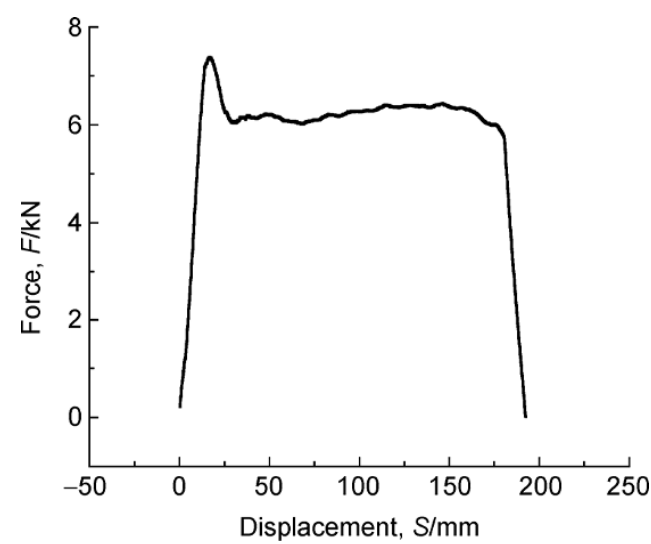

Fig. 11 Force vs. displacement for engraving nylon rotating band. firing conditions. The increased pressure acts on the projectile base throughout the engraving process and accelerates the projectile. In this study, we intend to achieve engraving of the rotating band into the forcing cone and ejection of the tested projectile from the gun barrel by only one impact. However, this intention was not reached initially when performing the dynamic engraving of the copper rotating band. At first, we set the $\mathrm{N}_{2}$ pressure to $0.3 \mathrm{MPa}$; the corresponding measured striker bar velocity was $2.88 \mathrm{~m} / \mathrm{s}$. The rotating band moved forward only by a few millimeters under the impact. Too large a contact area between the rotating band and the gun bore surface generated too high a resistance. Therefore, the pressure was adjusted to $0.4 \mathrm{MPa}, 0.5 \mathrm{MPa}$, and $0.6 \mathrm{MPa}$, and the corresponding striker velocities were $3.16 \mathrm{~m} / \mathrm{s}, 3.58 \mathrm{~m} / \mathrm{s}$, $4.03 \mathrm{~m} / \mathrm{s}$. Finally, when the pressure was increased to $0.7 \mathrm{MPa}$, the rotating band exited the gun barrel in one impact with a striker velocity of $4.64 \mathrm{~m} / \mathrm{s}$. To ensure that the projectile with engraved rotating band is ejected from the gun barrel in one impact, we can increase $\mathrm{N}_{2}$ pressure or decrease the rotating band diameter and width. Next, the nylon rotating band was engraved into the forcing cone in one impact under a $\mathrm{N}_{2}$ pressure $0.6 \mathrm{MPa}$, and the projectile was successfully ejected from the gun barrel.

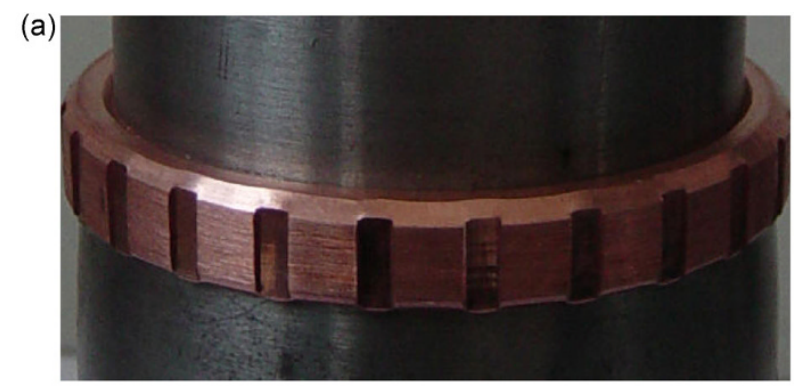

(b)

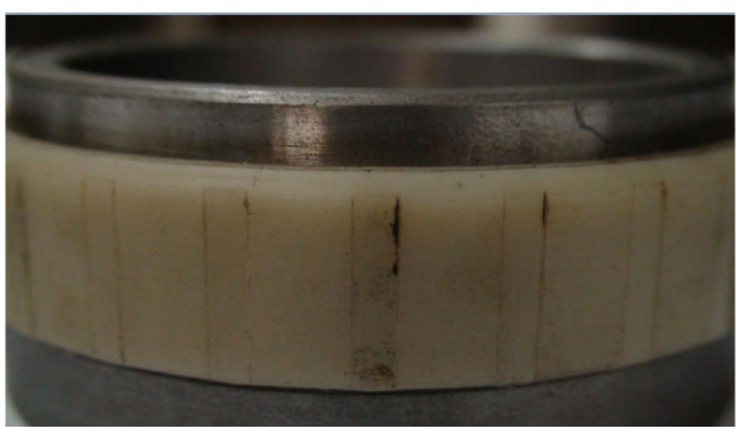

Fig. 12 Dynamically engraved rotating band: (a) copper; (b) nylon. 


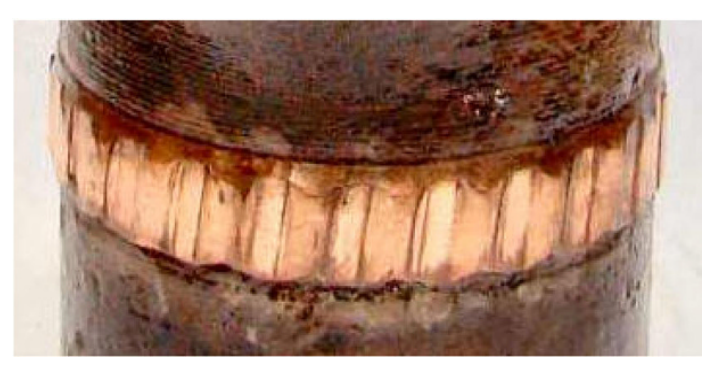

Fig. 13 Engraved rotating band of a recovered projectile.

Comparing with the quasi-statically engraved rotating bands, the dynamically engraved rotating bands did not have accumulated material at the end of every groove, indicating that the rotating bands were not extruded but cut by the lands under dynamic loading. The chips were observed after the dynamic loading tests. Furthermore, it was also found that the copper or brass was deposited on the grooves' surface after tests owing to severe friction between the groove and the rotating band. In fact, coppering always happens within the gun bore surface under actual firing conditions, and it should be eliminated to avoid any adverse effect on accuracy [17].

Figure 13 shows an engraved rotating band of a recovered projectile after actual firing. Obviously, the deformation behavior of engraved rotating bands under dynamic impact loading resembles that of a truly engraved rotating band under firing conditions. It can be deduced from different plastic deformation morphologies of the engraved rotating bands that loading rate plays a significant role in engraving of the rotating band.

\subsection{Morphology and plastic deformation}

Figure 14 shows the surface morphologies of the rotating band before and after engraving. Compared with the surface morphology of un-engraved rotating bands (Fig. 14(a)), those of the friction surfaces of engraved rotating bands exhibited obvious wear scars, as shown in Figs. 14(b) and 14(c). It can be seen that the quasi-statically engraved band surface suffered from more severe wear and deformation than then dynamically engraved band. This implies that engraving the rotating band at lower strain rates leads to larger deformation and resistance because the band material (copper) has adequate time to deform. Moreover, the heat induced due to band/bore friction (a)

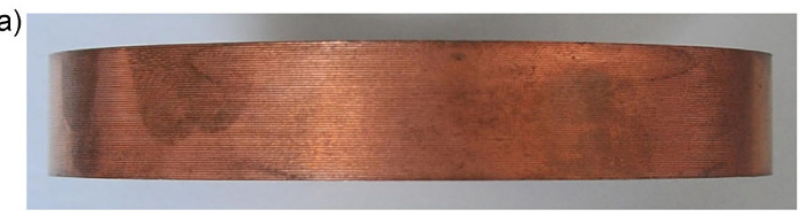

(b)
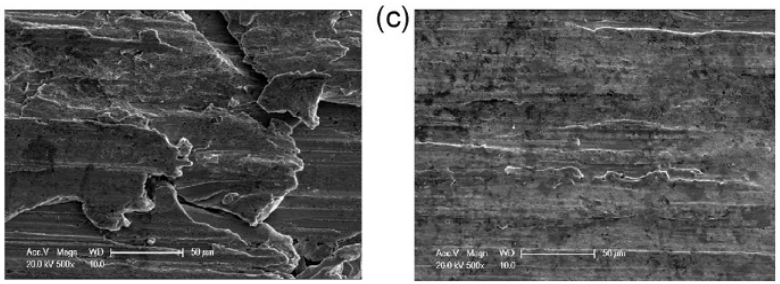

Fig. 14 Surface morphologies of rotating bands: (a) original; (b) quasi-static; (c) dynamic.

dissipated during the engraving process, and the band surface temperature remained nearly the same. However, when we touched the band surface as soon as the projectile was ejected from the barrel exit under impact loading, it felt warm. This indicates that its temperature rose because the generated heat could not be dissipated fully in such a short time. It should be noted that we do not yet have a method to measure the band surface temperature; the development of such a method is still under consideration.

Cross-sectional microstructures of the original and the engraved copper band samples are shown in Fig. 15. Evidence of plastic deformation is obvious in the surface layer to a depth of about $500 \mu \mathrm{m}$ for the quasi-statically engraved sample (Fig. 15(b)) and to a depth of about $300 \mu \mathrm{m}$ for the dynamically engraved sample (Fig. 15(c)). The deformation is inhomogeneous in terms of depth from place to place owing to the varying orientations of grains and the heterogeneous nature of plastic deformation within and between grains. It can be seen that the friction surface layer underwent more severe deformation during the quasistatic engraving process than that during the dynamic engraving process. The microstructure of the top surface is denser owing to high stress and large plastic deformation. This observation is in agreement with the surface morphologies. Figure 16 shows the hardness distribution from the top surface to the base. The total cross-section can be divided into three regions (I-severe deformation, II-slight deformation, III-undeformed) along the depth from the top friction surface. The denser microstructure has higher hardness than the original microstructure owing to strengthening by 
(a)

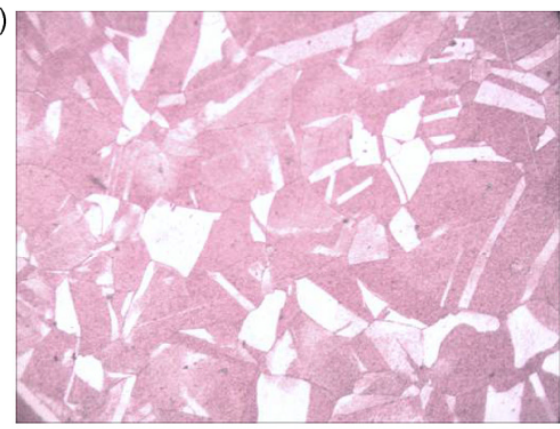

(b)

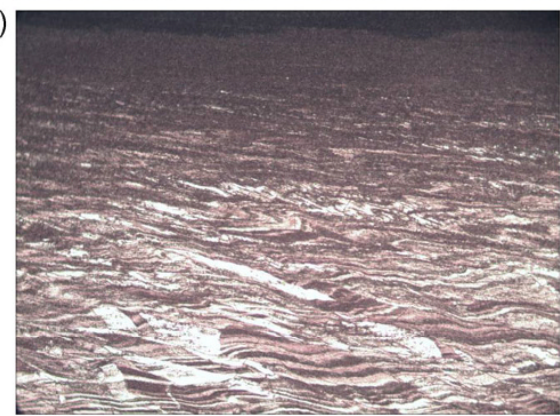

(c)

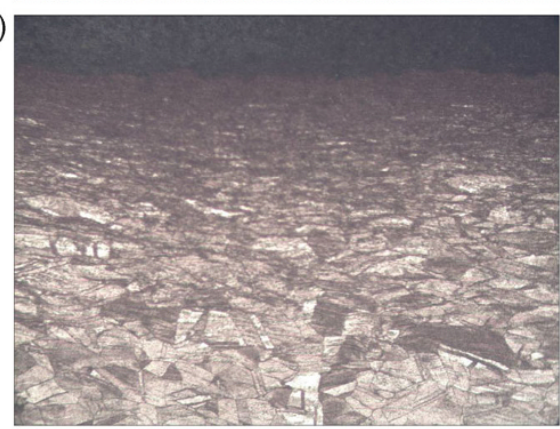

Fig. 15 Cross-sectional microstructure observations (500×): (a) original; (b) quasi-static; (c) dynamic.

(a)

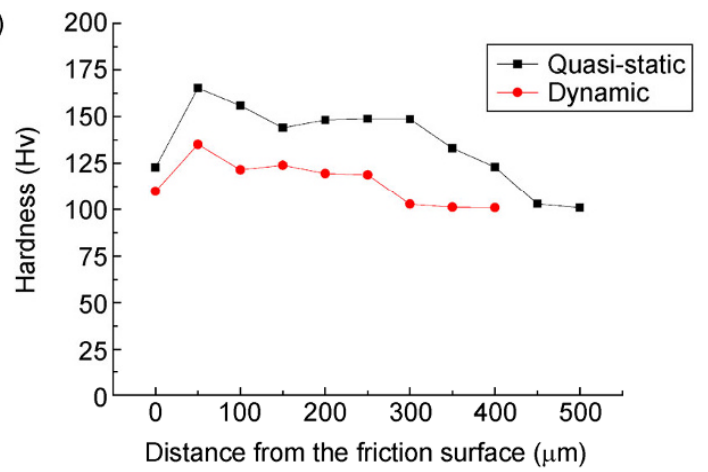

(b)

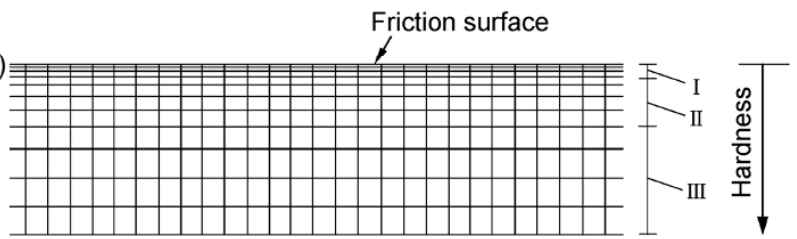

Fig. 16 Variation of hardness with depth from top surface under quasi-static and dynamic engraving conditions. plastic deformation. The measured hardness results are consistent with the changes in microstructure.

It can be deduced from Figs. 14-16 that the strain rate and temperature influence the behavior of the copper band significantly, which leads to a prominent difference between quasi-static and dynamic engraving. Figure 17 shows the results of the quasi-static and dynamic mechanical tests for copper under strain rates of $10^{-3}$ and $2 \times 10^{3} \mathrm{~s}^{-1}$, respectively. It is evident that the strain rate has a significant effect on specimen strength. As expected, the flow stress increases more rapidly in the dynamic regime than in the quasi-static regime. The yield strength in the dynamic tests is higher than that in the quasi-static tests. An increase in the strain rate leads to a reduction in work hardening. It is clear that the strengthening effect in the tested material varies with the strain rate. Furthermore, thermal softening, which results from the heating due to high strain rate impact loading, may influence the mechanical behavior of copper. Plastic deformation of conventional coarse-grained polycrystalline metals mainly happens at lattice dislocations within individual grains. Slip, twinning, and grain-boundary cracking are competing deformation mechanisms; the former being favored under quasi-static loading and the latter two under high-strain-rate conditions. Consequently, the material undergoes a ductile-to-brittle transition as the strain rate is increased from $10^{-3}$ to $10^{3} \mathrm{~s}^{-1}$. It is generally known that metals with a face-centered cubic (FCC) crystal structure, such as copper, are ductile and deform plastically owing to dislocation slip on

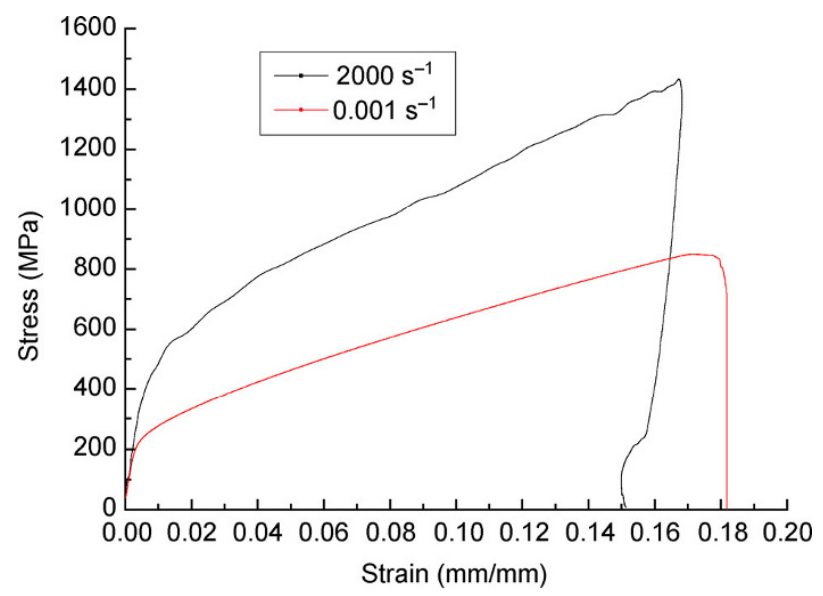

Fig. 17 Stress-strain curves of copper deformed under different strain rates. 
the (111) planes in the $\langle 110\rangle$ directions. Deformation twinning of FCC crystal structure metals occurs under very high strain rates according to Meyers et al. [18]. Cronje et al. [19] reported that deformation twinning in copper occurs under high strain rates (700 and $1400 \mathrm{~s}^{-1}$ ). Therefore, it is suggested that the engraving behavior of the rotating band can be attributed to the effects of strain rate and temperature. Comprehensive knowledge of the nature of engraving process is still being acquired and will be reported in the future.

\section{Conclusions}

In the present work, the interaction of copper and nylon rotating bands with the gun barrel during engraving was studied under the quasi-static and dynamic loading conditions. The main conclusions are summarized below:

(1) Structure of the gun bore and the rotating band influence the engraving process, indicating that optimal design of the structure is beneficial for obtaining the desired interior parameters such as muzzle velocity.

(2) Under the same testing condition, the engraving force of the copper rotating band is an order of magnitude higher than that of the nylon rotating band. This demonstrates that the addition of a nylon obturating band behind the copper rotating band in certain projectiles has nearly no influence on the engraving process, the function of which is to seal the combustion gases. Moreover, the difference in engraving force between copper and nylon suggests that the band material greatly influences the engraving process and should be chosen properly.

(3) The loading rate, which reflects the action of quasi-static loading, dynamic loading, and actual firing, plays a key role in engraving of the rotating band. The surface layer is condensed, strengthened, and possesses higher hardness owing to large deformation and severe friction. It is suggested that strain rate and temperature have great effects on the deformation behaviors of rotating bands.

\section{Acknowledgements}

The authors are very grateful to Dr. Xiang-gui Ni for his assistance to the engraving testing. This work was financially supported by the National Natural Science Foundation of China (NSFC) under Grant No. 51175512.

Open Access: This article is distributed under the terms of the Creative Commons Attribution License which permits any use, distribution, and reproduction in any medium, provided the original author(s) and source are credited.

\section{Reference}

[1] Montgomery R S. Interaction of copper-containing rotating band metal with gun bores at the environment present in a gun tube. Wear 33: 109-128 (1975)

[2] Montgomery R S. Friction and wear at high sliding speeds. Wear 36: 275-298 (1976)

[3] Montgomery R S. Surface melting of rotating bands. Wear 38: 235-243 (1976)

[4] Montgomery R S. Projectile lubrication by melting rotating bands. Wear 39: 181-183 (1976)

[5] Montgomery R S. Wear of projectile rotating bands. Wear 101: 347-356 (1985)

[6] Matsuyama T. Friction and wear mechanism at high sliding speeds. In $19^{\text {th }}$ International Symposium of Ballistics, 2001.

[7] Lisov M. Modeling wear mechanism of artillery projectiles rotating band using variable parametars of internal ballistic process. Scientific-Technical Review 56(2): 11-16 (2006)

[8] Andrews T D. Projectile driving band interactions with gun barrels. J Press Vess Tech 128: 273-278 (2006)

[9] Toivola J, Moilanen S, Tervokoski J, Keinänen H. Influence of rotating band construction on gun tube loading-Part II: Measurement and analysis. J Press Vess Tech 134: 041007 (2012)

[10] Keinänen H, Seppo Moilanen, Janne Tervokoski, Juha Toivola. Influence of rotating band construction on gun tube loading-Part I: Numerical Approach. J Press Vess Tech 134: 041006 (2012)

[11] Eleiche A M, Mokhtar M O A, Kamel G M A. Glass-fiber reinforced polyamide for rotating band application. In Proceedings of the World Congress on Engineering 2013 Vol III, London, UK, 2013.

[12] Balla J, Jankovych R, Duong V Y. Interaction between projectile driving band and forcing cone of weapon barrel. In Proceedings of the 13th IASME/WSEAS international conference on Mathematical Methods and Computational Techniques in Electrical Engineering conference on Applied Computing, 2011: 194-199 
[13] Chen P C T. Analysis of engraving and wear in a projectile rotating band. Technical Report ARCCB-TR-99012, 1999.

[14] Chen P C T, Leach M. Modeling of barrel/projectile interaction in a rotating band. Technical Report ARCCB-TR-01011, 2001.

[15] Wu B, Fang L, Chen X, Zou Z, Yu X, Chen G. Fabricating aluminum bronze rotating band for large-caliber projectiles by high velocity arc spraying. $J$ Therm Spray Techn 23(3): 447-455 (2014)

[16] Stiffler A K. Projectile sliding forces in a riled barrel. Int

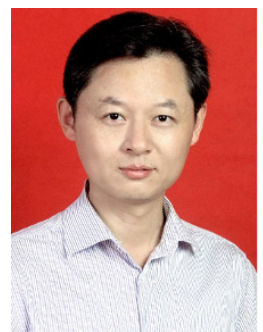

Bin WU. He received his Bachelor degree in Mechanical Engineering in 1993 from Hefei University of Technology, Anhui, China. After then, he joined the Army Officer Academy PLA. He received his $\mathrm{PhD}$ degree
J Mech Sci 25(2): 105-119 (1983)

[17] Vigilante G N, Bartolucci S, Izzo J, Witherell M, Smith S B. Gleeble testing to assess solid/liquid metal embrittlement of gun steels by copper. Mater Manuf Process 27(8): 835-839 (2012)

[18] Meyers M A, Vöhringer O, Lubarda V A. The onset of twinning in metals: A constitutive description. Acta Mater 49(19): 4025-4039 (2001)

[19] Cronje S, Kroon R E, Roos W D, Neethling J H. Twinning in copper deformed at high strain rates. Bull Mater Sci 36(1): 157-162 (2013)

in Mechanical Engineering at South China University of Technology, Guangdong, China in 2003. His current position is an Associate Professor and the Deputy Director of the department. His research areas cover the tribology of ballistics, surface engineering and remanufacturing. 